\title{
The Value of Monitoring the Behavior of Circulating Tumor Cells at the End of Endocrine Therapy in Breast Cancer Patients
}

\author{
Katharina Pachmann ${ }^{1, *}$ and Stefan Schuster ${ }^{2}$ \\ 1 Medizinisches Labor Pachmann, SIMFO GmbH, Kurpromenade 2, 95448 Bayreuth, Germany \\ 2 SIMFO GmbH, Kurpromenade 2, 95448 Bayreuth, Germany; sschuster@simfo.de \\ * Correspondence: kpachmann@laborpachmann.de; Tel.: +49-921-850-200
}

Received: 9 October 2018; Accepted: 26 October 2018; Published: 29 October 2018

check for updates

\begin{abstract}
After five years of endocrine therapy, patients with ER+ (estrogen receptor positive) breast cancer face the question of the benefit of further treatment. Ten years of endocrine therapy has been demonstrated to improve survival compared to five years. However, the individual benefit of continuation remains unclear. Therefore, markers for predicting benefit from endocrine treatment and extended endocrine treatment are desperately needed. In this study the dynamics over time of the tumor cells circulating in peripheral blood of patients, circulating tumor cells/ circulating epithelial tumor cells (CTC/CETC), as the systemic part of the tumor were investigated in 36 patients with ER+ primary breast cancer. CTC/CETCs were monitored serially during and after endocrine therapy. After termination of endocrine therapy 12 patients showed an increase in CTC/CETCs, with 8 of 12 suffering relapse. No change or a reduction was observed in 24 patients, with 2 of 24 suffering relapse. Initial tumor size was marginally prognostic $(p=0.053)$ but not nodal status nor the mere number of CTC/CETCs. Only the trajectory of CTC/CETCs was a statistically significant predictor of relapse free survival (increasing cell numbers: mean $=940$ days vs. stable/decreasing cell numbers mean not reached). Individual cases demonstrated that an increase of CTC/CETCs after discontinuation of tamoxifen therapy could be stopped by resuming the endocrine therapy.
\end{abstract}

Keywords: breast cancer; circulating tumor cells; endocrine therapy; longtime surveillance

\section{Introduction}

Until recently adjuvant chemotherapy was given to almost all primary breast cancer patients in order to prevent metastasis formation [1]. Since most chemotherapeutic agents are mainly active against proliferating cells it has long been known that this leads to overtreatment, especially in patients that have estrogen receptor positive breast cancer with a low fraction of proliferating cells [2]. Therefore, expression analyses from the primary tumor comprising genes which are involved in multiple cellular and cancer-associated processes such as cell cycle, proliferation, invasion, angiogenesis, and metastasis formation [3,4] were developed and the term precision oncology was used to describe the selection or deselection of adjuvant chemotherapy guided by these expression profiling tools. However, there is still no consensus as to whether these new tools will definitely be helpful. According to the German Institute for Quality and Efficiency in Healthcare (IQWiG) [5] to date there is no evidence neither of benefit nor harm of a biomarker-based strategy for the decision for or against chemotherapy in primary early stage estrogen receptor positive breast cancer. Therefore, it remains the decision of the patient who may mull for years over whether she has made the right decision.

More recently mutation analyses used to guide targeted therapy in different cancer types are referred to as precision medicines but, so far, relevant mutations are difficult to detect in early breast cancer and as a matter of principle the success of such an approach has recently been challenged [6]. 
In contrast, endocrine therapy was established as the earliest and most successful targeted (precision) therapy in hormone receptor positive breast cancer and it seems to have the strongest impact on relapse-free and overall survival [7].

Endocrine therapy is unequivocally accepted in all hormone receptor positive patients in contrast to chemotherapy [2] and currently is scheduled for five years. Obviously, treatment with Tamoxifen benefits these patients [8]. But even after five years of effective therapy with selective estrogen receptor modulators (SERM), relapses still occur. The ATLAS (Adjuvant Tamoxifen: Longer Against Shorter) study demonstrated that 10 years administration of Tamoxifen is superior to that of 5 years [9] which has been confirmed recently by the aTTom study [10].

Some of the side effects of tamoxifen treatment like thrombotic events and embolism as well as endometriosis and endometrial cancer are serious [11], and for most women five years of treatment with hormone blockers already poses a problem which often requires motivating discussions with the patient. For the individual woman it remains unclear whether she may benefit from extended endocrine therapy and patients and care providers bemoan that during follow-up neither frequent serum tumor marker determination nor imaging for early detection of relapse is recommended [12], with only local monitoring being advised. Serial follow up of the number of the circulating cells suspect to be of tumor origin (CETC/CTC) in blood during and after completion of chemotherapy [13] may contribute to closing this diagnostic gap.

It is well known that cells are able to break away from malignant tumors and circulate in blood. These macroscopically undetectable circulating tumor cells remaining in the body can contribute to (the development of) metastases [14]. Our results indicate that tamoxifen may not kill most cancer cells but most probably drives them into dormancy [15]. They may then become active after the termination of therapy, leading to tumor growth locally and/or as distant metastases.

Using the maintrac ${ }^{\circledR}$ approach, carcinoma-derived cells can be detected without enrichment among the other blood cells due to the surface expression of EpCAM (epithelial cell adhesion molecule) specific for epithelial cells (Figure 1) [16].
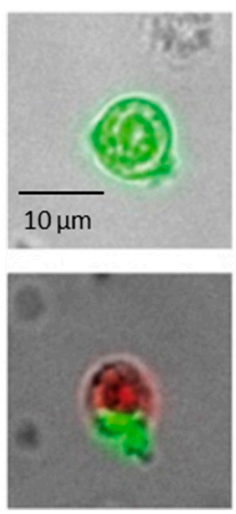
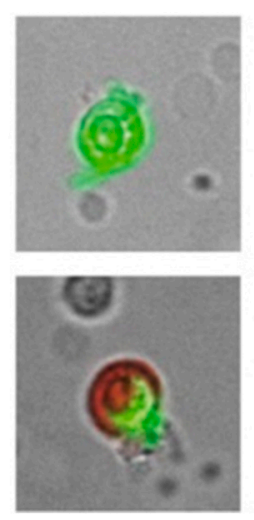
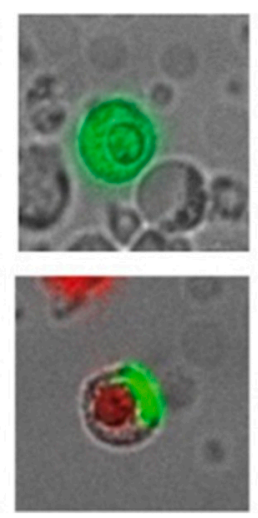
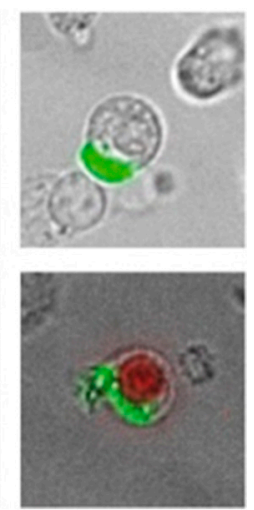

Figure 1. Typical gallery of images of live (EpCAM fluorescein-isothiocyanate (FITC) green) and dead (green and red Propidium Iodide Uptake) tumor suspect cells of one patient. Dead cells are not included into the cell count.

Although benign epithelial cells can enter the bloodstream through various events including injuries, burns, inflammatory diseases, and surgical procedures $[17,18]$, these cells are usually rapidly removed from the circulation, whereas epithelial tumor cells can survive up to 20 years $[19,20]$ and can recirculate in blood [21]. These cells can be monitored in peripheral blood not only during chemotherapy [14] but it is also possible to follow their evolution during endocrine treatment [22]. An increase in cell numbers generally indicates increased tumor activity and is associated with a poor prognosis, whereas a decrease in cell numbers indicates successful treatment and a good prognosis [23]. Thus, the key part in monitoring therapy with the maintrac ${ }^{\circledR}$ method is not a one-off measurement, but the analysis of the dynamics of cell numbers over a prolonged period. 
The present report demonstrates that this is also true after discontinuation of endocrine treatment. Most importantly, we show that an increase in cell numbers after the end of endocrine treatment is of highly significant clinical relevance but that a (re-)uptake of therapy can lead to re-decreasing CETC and to potentially minimize the risk of developing metastases. Thus, it is possible in early breast cancer patients to identify patients for which a prolonged endocrine therapy is necessary within a period of weeks after terminating the previous round of medication.

\section{Results}

The patient population comprised 36 patients with hormone receptor positive tumors who received tamoxifen or an aromatase inhibitor as endocrine therapy for hormone receptor positive primary breast cancer for up to 5 years. The median time of initial diagnosis was 7 years prior to assessment. The median observation period after completion of endocrine therapy was 608 days (range, 14-2, 159 days). Further patient characteristics are listed in Table 1.

Table 1. Patient population.

\begin{tabular}{|c|c|c|}
\hline \multicolumn{3}{|c|}{ Patient Population } \\
\hline Number of patients & 36 & \\
\hline Age $\quad 1$ & $31-80$ & \\
\hline Relapse & 10 & \\
\hline Mean age patients relapsed & 43 & \\
\hline Mean age patients in complete remission & 56 & Ns \\
\hline Observation period after endocrine therapy & 608 days * & \\
\hline Observation period after initial diagnosis & 2281 days * & \\
\hline \multicolumn{3}{|l|}{ CETCs } \\
\hline Increasing & 12 & Rel 8 \\
\hline Decreasing/Constant & 24 & Rel 2 \\
\hline \multicolumn{3}{|l|}{ Tumor Size } \\
\hline T1 & 20 & Rel 3 \\
\hline$>\mathrm{T} 2$ & 15 & Rel 7 \\
\hline Unknown & 1 & \\
\hline \multicolumn{3}{|l|}{ Nodal Status } \\
\hline No & 24 & Rel 6 \\
\hline N1-2 & 12 & Rel 4 \\
\hline
\end{tabular}

* Observation periods are reported as median values. CETCs $=$ circulating epithelial tumor cells. $(\mathrm{Ns}=$ not significant, $\mathrm{Rel}=$ Relapse) .

20 patients had T1 (55\%) tumors and 15 patients T2 and larger (42\%), 1 with unknown size (3\%). Lymph node status was N0 in 24 patients and N1-2 in 12 patients.

CETC behavior in 36 patients was significantly correlated with recurrence after endocrine therapy $(p=0.006)$. After the end of endocrine therapy, an increase in CETCs was observed in 12 patients, of whom 8 patients suffered relapse. The cell count remained stable or decreased in 24 patients even after completion of endocrine therapy. In this group, two patients relapsed during the course of the study (Figure 2).

Established prognostic factors such as tumor size or nodal status were not predictive of prognosis nor were age in this patient population after the end of endocrine therapy. While tumor size indicated a tendency ( $p=0.058$; Figure 3a) for tumors bigger than T1 size to have a poorer prognosis (only one patient had a tumor bigger than T2), neither the nodal status (Figure 3b) nor age (Figure 3c) was significant for recurrence-free survival after endocrine therapy in this small patient cohort. 


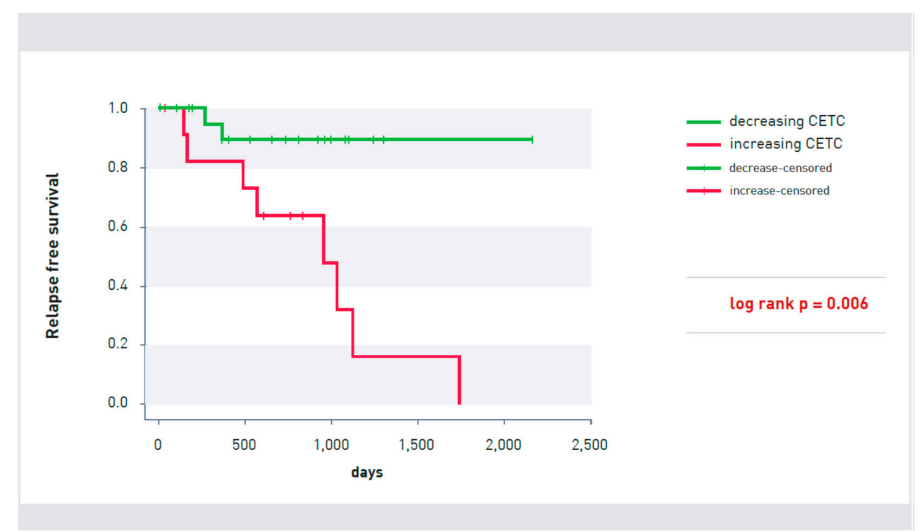

Figure 2. Kaplan-Meier survival curve of patients with increasing (red line) and decreasing (green line) CETCs $(p=0.006)$. Patients without signs of relapse at the last visit were censored.

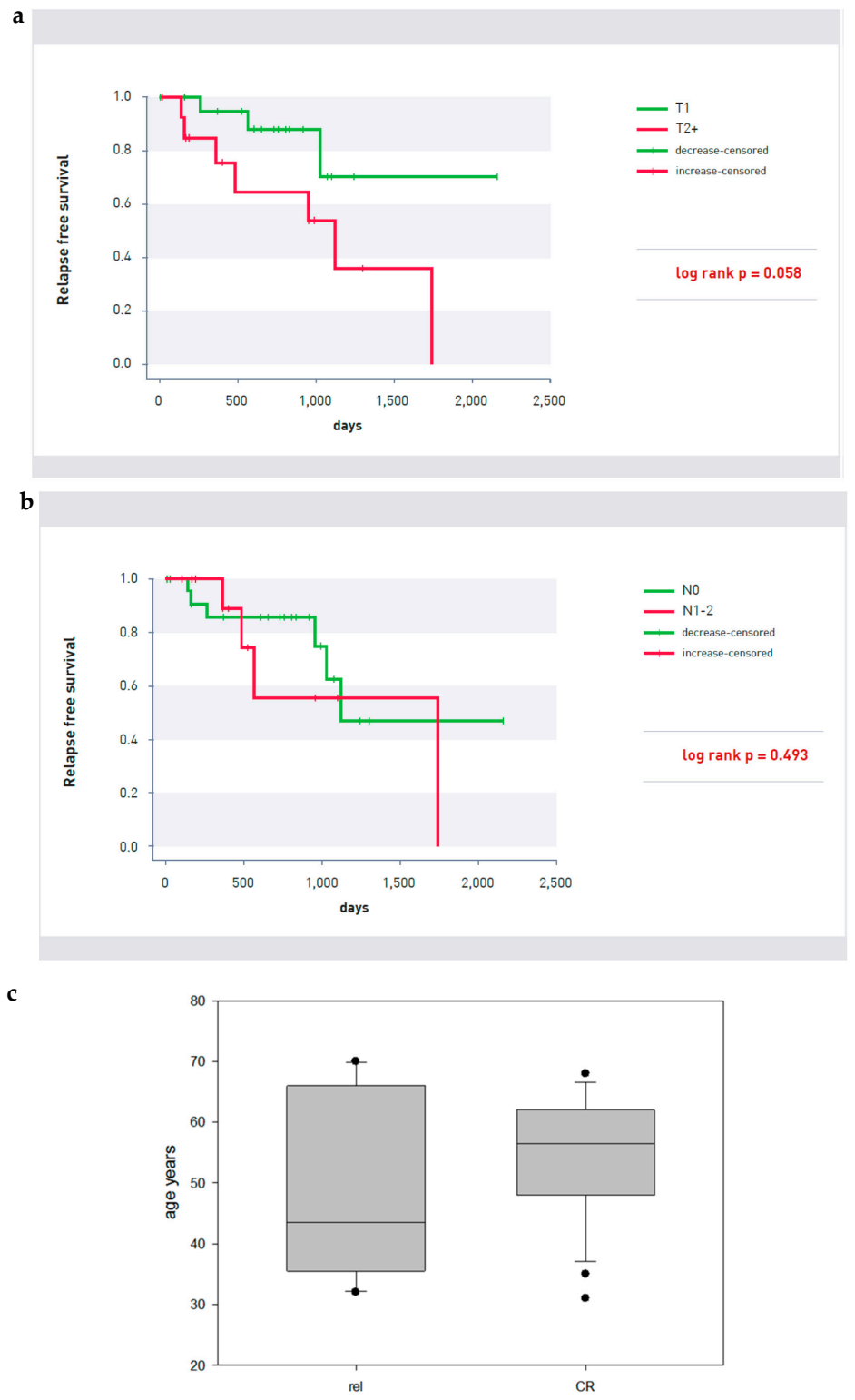

Figure 3. (a) Kaplan-Meier survival curve of patients with $\mathrm{T} 2$ as well as larger (red line) $\mathrm{T} 1$ size tumors (green line) ( $p=0.058)$. (b) Kaplan-Meier survival curve of patients with (red line) and without lymph node involvement (green line) $(p=0.493)$. (c) Age distribution of patients with $(\mathrm{R})$ and without relapse (CR) (Mann-Whitney U test $p=0.512$ ). 
Typical courses of circulating tumor cells of two patients from the study population are shown in Figure 4a,b.

The first patient showed an increase in CETCs during radiotherapy. Subsequently, her number of CETCs remained fairly constant for three years under Tamoxifen treatment and even 2 years after terminating treatment. She is relapse free as of the present day (Figure 4a). The second patient demonstrated considerable variation of CETCs under the 5-years-therapy with Tamoxifen (Figure 4b). Due to pre-menopausal status the patient received the GnRH analogue Gosereline in addition to Tamoxifen, for the first 2 years. Under further Tamoxifen therapy complete elimination of CETCs from the circulation was observed.

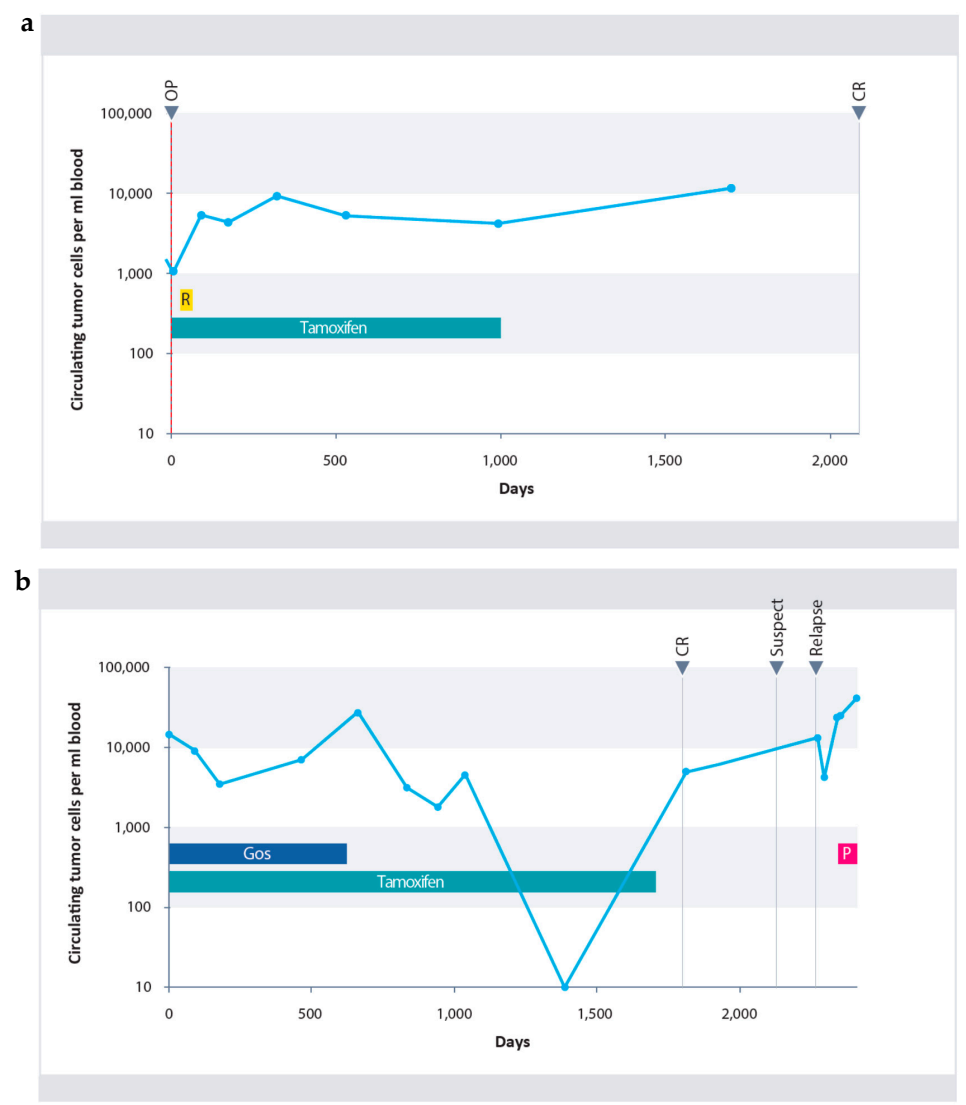

Figure 4. (a) Course of CETCs in a patient with invasive ductal carcinoma (pT1bpN2aM0). Initially, an increase in cell numbers under radiotherapy was observed (hatched in yellow). Cell numbers remained primarily constant under further Tamoxifen therapy (blue). Follow-up samples of the patient revealed macroscopic complete remission (CR). (b) Course of CETCs in a patient with invasive lobular carcinoma who was treated with neoadjuvant therapy (ypT1a(m)pN1aM0). Under combined therapy comprising of Goserelin (hatched in dark blue) and Tamoxifen (blue), an initial decrease in CETCs was observed, followed by a renewed increase during further combination therapy. Under monotherapy with Tamoxifen a continuous decrease in CETCs was observed followed by a renewed increase of CETCs after completion of endocrine therapy. At that time the patient was macroscopically still in complete remission. After additional 10 months recurrence was confirmed and after mastectomy was treated with Paclitaxel (purple).

However, four months after completion of endocrine therapy, the patient's cell count increased drastically, although there was no indication of relapse at examination. The numbers continued to increase and 10 months later, relapse was detected and after mastectomy, was treated with weekly Paclitaxel.

Additionally, 3 cases are presented where Tamoxifen therapy was terminated due to side effects but subsequently resumed upon recommendation. 
In the three patients shown in Figure 5a-c we were able to show that if endocrine therapy was reinitiated (Tamoxifen or aromatase inhibitor, such as Letrozol) after an increase of CETC during adjournment of therapy, cell numbers re-declined and the patients have remained relapse free so far.
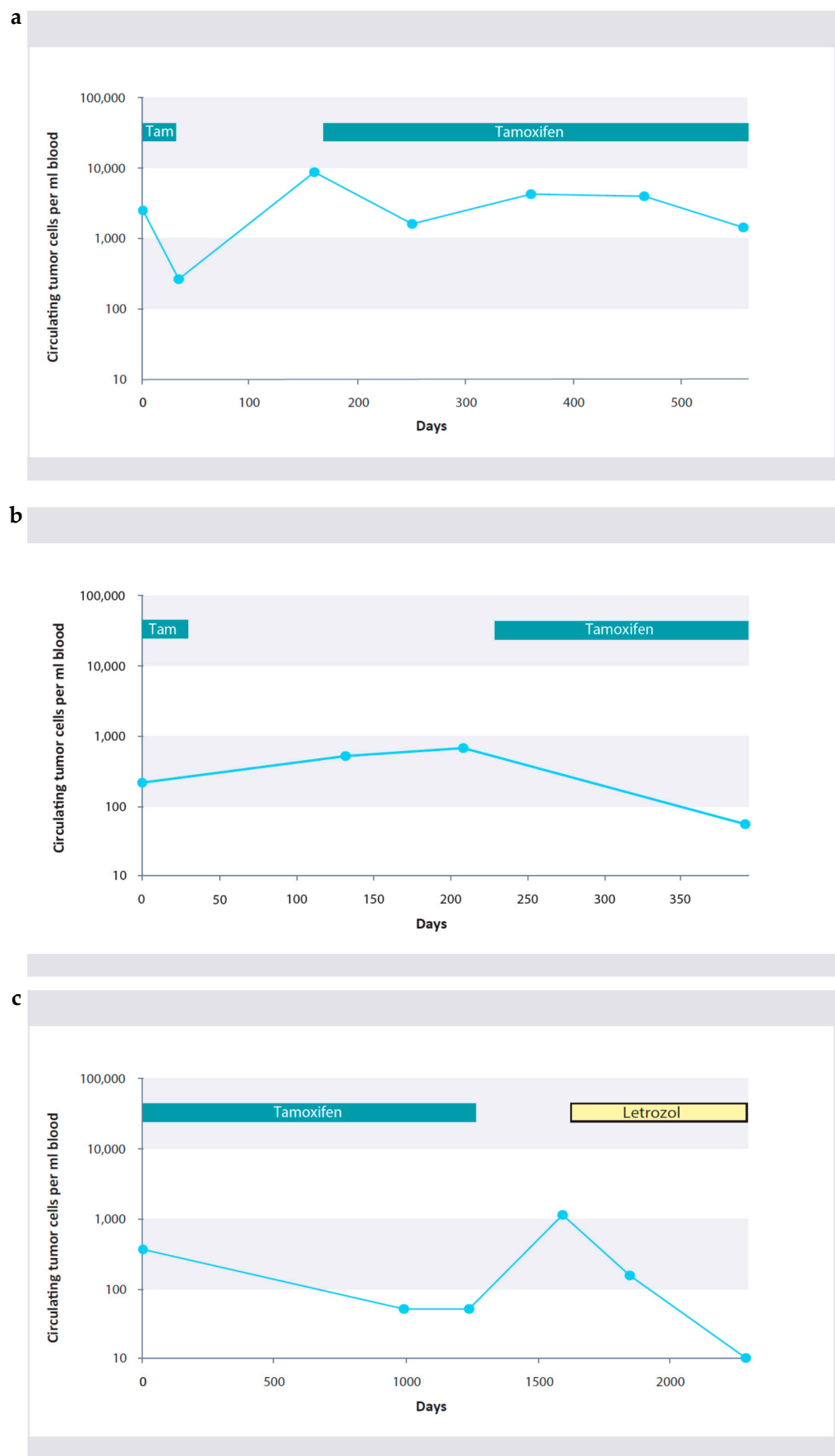

Figure 5. (a) Breast cancer (pT1cN0M0G2, HR+, Her2/neu: neg). 4 times TC (taxane and cyclophosphamide). Tamoxifen interrupted because of side effects. Reiinitiation of Tamoxifen. (b) Breast Cancer (pT2pN0M0). 6 times FEC (fluoruracil, epirubicine and cyclophophasmide, Herceptin, Radiatio, Tamoxifen interrupted. Reiinitiation of Tamoxifen. (c) Breast Cancer (pT2pN2apM0G3) Er+ PR+ Her2/neu FISH neg, 3 times FEC, 3 times Docetaxel, Radiatio, Tamoxifen interrupted, then Letrozol. 


\section{Discussion}

Detection and serial monitoring of cells expressing the epithelial surface molecule EpCAM in peripheral blood of patients with hormone receptor positive breast cancer was used to follow the fate of these cells during endocrine e treatment. Although expressed by most cancer cells, EpCAM is not confined to malignant cells but also found on normal epithelial cells. Dead cells or macrophages may take up anti-EpCAM antibody non-specifically but this was excluded by analyzing only live cells with strictly surface located expression. If normal epithelial cells are accidentally released into blood they are not expected to increase in numbers. In contrast, epithelial tumor cells are assumed to be shed into blood continuously during tumor growth [24].

Therefore, a single determination of the number of epithelial cells suspect to be of tumor origin, circulating in blood which we have termed CETCs, may have little prognostic relevance in primary tumors. However, repeated blood drawing allows for the detection of CETCs at any time point during the course of disease making serial monitoring possible. An increase in numbers of these cells generally has been shown to indicate increased tumor activity and was associated with poor prognosis, whereas a decrease in cell numbers indicates successful treatment and a good prognosis as shown in various studies under different therapies involving more than 650 patients [17,18,22,25-27].

The present results where a relapse after the end of endocrine therapy was observed in 8 of 12 patients with increasing cell numbers and only in 2 of 24 patients with decreasing or stable cell numbers confirm the above observations also apply in the situation of endocrine maintenance therapy.

This allows to individually monitor patients, particularly if a decision is pending on whether to terminate e.g., endocrine therapy. Careful and consequent examination of patients to determine whether cell numbers have a tendency to increase again after the end of therapy, could reveal increased tumor activity at an early stage. Quantitative serial monitoring of living epithelial tumor cells can then help to assess whether extended endocrine therapy in these patients has an impact on their circulating cells and the course of disease. The observation of the nodal status not being of significance was initially surprising; however, this finding may have been related to the long observation period. After initial diagnosis, the median observation period of patients was 7 years. It is known that in patients with a high nodal status relapse occurs at an early stage [28]. In the present study, this patient cohort was underrepresented. This most probably also applies for tumor size, although a tendency for relapse after endocrine therapy was observed for larger tumors.

The measurement of CETCs in blood provides breast cancer patients the opportunity to monitor their course of the disease. After the completion of endocrine therapy, the observation of increasing CETCs in a routine setting could lead to two plausible scenarios: Either the increase should lead to further diagnostic measures allowing for the early initiation of interventional treatment or the direct reuptake of the endocrine treatment. The first scenario has the advantage that therapeutic interventions can be taken within the established guideline if a macroscopic relapse is detected. The second allows for detecting tumor activity using CETCs already when even highly sensitive imaging is not able to detect a relapse but it is not included within the guidelines. Both scenarios offer the possibility that a relapse will be detected earlier. To determine if this leads to longer survival of the patients, further studies are needed.

\section{Methods and Patients}

The patients were recruited at the University Hospital of Jena between 2001 and 2012. All patients had estrogen receptor positive breast cancer, confirmed by histopathology. Only patients without metastasis were included in this study, independent from their menopausal status. Patients received either adjuvant or neoadjuvant treatment. This population represents a subgroup of patients that have been monitored during endocrine treatment and which has been published previously [22].

Ethical approval was given by the University of Jena on 13 September 2002, ethical Code 0921-08/02. The maintrac ${ }^{\circledR}$ approach was used for detection and quantification of CETCs, as reported previously [23]. CETCs were determined from whole blood without enrichment. Blood samples were 
drawn into blood count tubes with ethylene diamine-tetra-acetic-acid (EDTA) for enumeration of CETCs. In brief, $1 \mathrm{~mL}$ blood was subjected to red blood cell lysis using $15 \mathrm{~mL}$ of erythrocyte lysis solution (Qiagen, Hilden, Germany). The solution was then cooled for $15 \mathrm{~min}$, spun down at $700 \mathrm{~g}$ and re-diluted in $500 \mathrm{~mL}$ of PBS-EDTA. $5 \mu \mathrm{L}$ of fluorescein-isothiocyanate (FITC)-conjugated mouse anti-human epithelial antibody (EpCAM) (Miltenyi Biotec GmbH, Bergisch Gladbach, Germany) was added and incubated for $15 \mathrm{~min}$ at $4{ }^{\circ} \mathrm{C}$. Subsequently, the samples were diluted with $430 \mu \mathrm{L}$ PBS-EDTA and then stored over night at $4{ }^{\circ} \mathrm{C}$. A defined volume of the cell suspension and propidium iodide (Sigma-Aldrich, St. Louis, MO, USA) was transferred to a 96-wells plate (Greiner Bio-one, Kremsmünster, Austria), evaluated with a fluorescence scanning microscope scanR (OLYMPUS EUROPA SE \& CO. KG, Hamburg, Germany,) and visually examined for the presence of fluorescence and cell morphology. Only live CETCs were counted with positive EpCAM fluorescence, lacking nuclear PI staining, and with intact morphology (Figure 1). Two types of quality controls were used for ensuring the consistent analysis of samples: Isotype control, as a negative control to measure the level of non-specific background signal and fluorospheres (Flow-Check 770, Beckman Coulter, Brea, CA, USA) for the daily verification of optical components and detectors. The number of CETCs in blood was repeatedly measured during and after completion of endocrine therapy. An increase or decrease in cell numbers was assumed as soon as cell numbers were altered by at least a factor of five following the termination of endocrine treatment. The mean period for CETC to increase was 631 days (range 60 to 1401 days).

Statistical analyses were calculated by the Kaplan-Meier method and differences of relapse free survival were compared by the log-rank test using SigmaPlot 13 for Windows (Systat Software Inc., San Jose, CA, USA). $p<0.05$ was considered to indicate a statistically significant difference.

\section{Conclusions}

In recent years, Tamoxifen therapy has clearly been demonstrated to be beneficial for patients with hormone receptor positive breast cancer despite known side effects, such as thrombosis, postmenopausal symptoms, and an increased long-term risk of endometrial cancer. Aromatase inhibitors have become an option in the treatment of hormone receptor positive breast cancer, especially if the side effects of Tamoxifen treatment are no longer tolerable.

CETC may provide valuable insights in the tumor activity to track relapses early and also to distinguish between effective and less effective therapies. Having observed fluctuations in cell numbers in patients with an irregular Tamoxifen intake, we found that in patients with increasing cell numbers after stopping endocrine treatment re-intake of Tamoxifen or switch to aromatase inhibitors again reduced the number of circulating tumor cells and no patient suffered from relapse in the observation period. This led us to assume that a re-uptake of endocrine therapy may be beneficial in patients with increasing cell numbers and might be able to prevent or at least delay recurrence. These first results are already promising.

Further studies are needed to clarify if for patients with increasing cell numbers a resumption of endocrine therapy is advantageous to prevent metastasis formation. Currently an interventional trial is planned to investigate this option based on the results of CETCs using the maintrac ${ }^{\circledR}$ approach. This would then provide a basis by which patients and therapists can make an individual decision about whether endocrine therapy should be continued or reinitiated. The response to treatment in each individual patient may be more important than the initial clinical or biologic features because these characteristics can change during the course of the disease.

Author Contributions: Both authors contributed equally to the manucscript.

Funding: This research received no external funding.

Conflicts of Interest: Katharina Pachmann owns patents for the herein described method maintrac to detect CETCs. 


\section{References}

1. Anampa, J.; Makower, D.; Sparano, J.A. Progress in adjuvant chemotherapy for breast cancer: An overview. BMC Med. 2015, 13. [CrossRef] [PubMed]

2. Gnant, M.; Steger, G.G. Fighting overtreatment in adjuvant breast cancer therapy. Lancet 2009, 374, $2029-2030$. [CrossRef]

3. Cardoso, F.; van't Veer, L.J.; Bogaerts, J.; Slaets, L.; Viale, G.; Delaloge, S.; Pierga, J.-Y.; Brain, E.; Causeret, S.; DeLorenzi, M.; et al. 70-Gene Signature as an Aid to Treatment Decisions in Early-Stage Breast Cancer. N. Engl. J. Med. 2016, 375, 717-729. [CrossRef] [PubMed]

4. Shak, S.; Petkov, V.; Miller, D.P.; Howlader, N.; Gliner, N.; Howe, W.; Schussler, N.C.; Cronin, K.; Baehner, F.L.; Penberthy, L. Breast cancer specific mortality in patients with early-stage hormone receptor-positive invasive breast cancer and oncotype DX recurrence score results in the SEER database. J. Clin. Oncol. 2016, 34, 176. [CrossRef]

5. IQWiG-Berichte Nr. 457, Biomarkerbasierte Tests zur Entscheidung für Oder Gegen Eine Adjuvante Systemische Chemotherapie Beim PrimäRen Mammakarzinom Abschlussbericht. Stand: 27.10.2016 Auftrag: D14-01 Version: 1.0. Available online: https://www.iqwig.de/de/projekte-ergebnisse/ projekte/nichtmedikamentoese-verfahren/d14-01-biomarkerbasierte-tests-zur-entscheidung-furoder-gegen-eine-adjuvante-systemische-chemotherapie-beim-primaren-mamma-karzinom.6097.html (accessed on 19 July 2018).

6. Carter, H.; Chen, S.; Isik, L.; Tyekucheva, S.; Velculescu, V.E.; Kinzler, K.W.; Vogelstein, B.; Karchin, R. Cancer-Specific High-Throughput Annotation of Somatic Mutations: Computational Prediction of Driver Missense Mutations. Cancer Res. 2009, 69, 6660-6667. [CrossRef] [PubMed]

7. Jordan, V.C. Tamoxifen Resistance Trumped and Oral Selective Estrogen Receptor Degraders Arrive. Clin. Cancer Res. 2018, 24, 3480-3482. [CrossRef] [PubMed]

8. Early Breast Cancer Trialists' Collaborative Group (EBCTCG). Relevance of breast cancer hormone receptors and other factors to the efficacy of adjuvant tamoxifen: Patient-level meta-analysis of randomised trials. Lancet 2011, 378, 771-784. [CrossRef]

9. Davies, C.; Pan, H.; Godwin, J.; Gray, R.; Arriagada, R.; Raina, V.; Abraham, M.; Alencar, V.H.M.; Badran, A.; Bonfill, X.; et al. Long-term effects of continuing adjuvant tamoxifen to 10 years versus stopping at 5 years after diagnosis of oestrogen receptor-positive breast cancer: ATLAS, a randomised trial. Lancet 2013, 381, 805-816. [CrossRef]

10. Gray, R.G.; Rea, D.; Handley, K.; Bowden, S.J.; Perry, P.; Earl, H.M.; Poole, C.J.; Bates, T.; Chetiyawardana, S.; Dewar, J.A.; et al. Long-term effects of continuing adjuvant tamoxifen to 10 years versus stopping at 5 years in 6953 women with early breast cancer. J. Clin. Oncol. 2013, 31, 5. [CrossRef]

11. Pan, H.; Gray, R.; Braybrooke, J.; Davies, C.; Taylor, C.; McGale, P.; Peto, R.; Pritchard, K.I.; Bergh, J.; Dowsett, M.; et al. 20-Year Risks of Breast-Cancer Recurrence after Stopping Endocrine Therapy at 5 Years. N. Engl. J. Med. 2017, 377, 1836-1846. [CrossRef] [PubMed]

12. Hahn, E.E.; Tang, T.; Lee, J.S.; Munoz-Plaza, C.E.; Shen, E.; Rowley, B.; Maeda, J.L.; Mosen, D.M.; Ruckdeschel, J.C.; Gould, M.K. Use of posttreatment imaging and biomarkers in survivors of early-stage breast cancer: Inappropriate surveillance or necessary care? Cancer 2016, 122, 908-916. [CrossRef] [PubMed]

13. Fidler, I.J. The pathogenesis of cancer metastasis: The "seed and soil" hypothesis revisited. Nat. Rev. Cancer 2003, 3, 453-458. [CrossRef] [PubMed]

14. Pachmann, K.; Camara, O.; Kavallaris, A.; Krauspe, S.; Malarski, N.; Gajda, M.; Kroll, T.; Jörke, C.; Hammer, U.; Altendorf-Hofmann, A.; et al. Monitoring the response of circulating epithelial tumor cells to adjuvant chemotherapy in breast cancer allows detection of patients at risk of early relapse. J. Clin. Oncol. 2008, 26, 1208-1215. [CrossRef] [PubMed]

15. Jun, Z.; Xiaolong, Q.; Fangfang, L.; Xiaojing, G.; Feng, G.; Li, F. Silencing of syndecan-binding protein enhances the inhibitory effect of tamoxifen and increases cellular sensitivity to estrogen. Cancer Biol. Med. 2018, 15, 29. [CrossRef] [PubMed]

16. Munz, M.; Baeuerle, P.A.; Gires, O. The Emerging Role of EpCAM in Cancer and Stem Cell Signaling. Cancer Res. 2009, 69, 5627-5629. [CrossRef] [PubMed] 
17. Rolle, A.; Günzel, R.; Pachmann, U.; Willen, B.; Pachmann, K. Increase in number of circulating disseminated epithelial cells after surgery for non-small cell lung cancer monitored by MAINTRAC ${ }^{\circledR}$ is a predictor for relapse: A preliminary report. World J. Surg. Oncol. 2005, 3. [CrossRef] [PubMed]

18. Camara, O.; Kavallaris, A.; Nöschel, H.; Rengsberger, M.; Jörke, C.; Pachmann, K. Seeding of epithelial cells into circulation during surgery for breast cancer: The fate of malignant and benign mobilized cells. World J. Surg. Oncol. 2006, 4. [CrossRef] [PubMed]

19. Chambers, A.F.; Naumov, G.N.; Vantyghem, S.A.; Tuck, A.B. Molecular biology of breast cancer metastasis Clinical implications of experimental studies on metastatic inefficiency. Breast Cancer Res. 2000, 2. [CrossRef]

20. Meng, S.; Tripathy, D.; Frenkel, E.P.; Shete, S.; Naftalis, E.Z.; Huth, J.F.; Beitsch, P.D.; Leitch, M.; Hoover, S.; Euhus, D.; et al. Circulating tumor cells in patients with breast cancer dormancy. Clin. Cancer Res. 2004, 10, 8152-8162. [CrossRef] [PubMed]

21. Pachmann, K. Longtime Recirculating Tumor Cells in Breast Cancer Patients. Clin. Cancer Res. 2005, 11, 5657-5658. [CrossRef] [PubMed]

22. Pachmann, K.; Camara, O.; Kohlhase, A.; Rabenstein, C.; Kroll, T.; Runnebaum, I.B.; Hoeffken, K. Assessing the efficacy of targeted therapy using circulating epithelial tumor cells (CETC): The example of SERM therapy monitoring as a unique tool to individualize therapy. J. Cancer Res. Clin. Oncol. 2011, 137, 821-828. [CrossRef] [PubMed]

23. Pachmann, K.; Clement, J.H.; Schneider, C.-P.; Willen, B.; Camara, O.; Pachmann, U.; Höffken, K. Standardized quantification of circulating peripheral tumor cells from lung and breast cancer. Clin. Chem. Lab. Med. 2005, 43. [CrossRef] [PubMed]

24. Lee, V.W.; Chiang, T.; Deodhar, S.D. Bioassay for quantitating circulating tumor cells in a syngeneic mouse tumor system. Cancer Res. 1976, 36, 2053-2058. [PubMed]

25. Camara, O.; Rengsberger, M.; Egbe, A.; Koch, A.; Gajda, M.; Hammer, U.; Jorke, C.; Rabenstein, C.; Untch, M.; Pachmann, K. The relevance of circulating epithelial tumor cells (CETC) for therapy monitoring during neoadjuvant (primary systemic) chemotherapy in breast cancer. Ann. Oncol. 2007, 18, 1484-1492. [CrossRef] [PubMed]

26. Lobodasch, K.; Fröhlich, F.; Rengsberger, M.; Schubert, R.; Dengler, R.; Pachmann, U.; Pachmann, K. Quantification of circulating tumour cells for the monitoring of adjuvant therapy in breast cancer: An increase in cell number at completion of therapy is a predictor of early relapse. Breast 2007, 16, 211-218. [CrossRef] [PubMed]

27. Pachmann, K.; Camara, O.; Kroll, T.; Gajda, M.; Gellner, A.K.; Wotschadlo, J.; Runnebaum, I.B. Efficacy control of therapy using circulating epithelial tumor cells (CETC) as "Liquid Biopsy": Trastuzumab in HER2/neu-positive breast carcinoma. J. Cancer Res. Clin. Oncol. 2011, 137, 1317-1327. [CrossRef] [PubMed]

28. Fisher, B.; Bauer, M.; Wickerham, D.L.; Redmond, C.K.; Fisher, E.R.; Cruz, A.B.; Foster, R.; Gardner, B.; Lerner, H.; Margolese, R.; et al. Relation of number of positive axillary nodes to the prognosis of patients with primary breast cancer. An NSABP update. Cancer 1983, 52, 1551-1557. [CrossRef]

(C) 2018 by the authors. Licensee MDPI, Basel, Switzerland. This article is an open access article distributed under the terms and conditions of the Creative Commons Attribution (CC BY) license (http:/ / creativecommons.org/licenses/by/4.0/). 